\title{
Complete remission after first-line radio-chemotherapy as predictor of survival in extranodal NK/T cell lymphoma
}

\author{
Adrien Chauchet ${ }^{1}$, Anne-Sophie Michallet ${ }^{1,11^{*}}$, Françoise Berger ${ }^{2}$, Isabelle Bedgedjian ${ }^{3}$, Eric Deconinck ${ }^{4}$, \\ Catherine Sebban ${ }^{5}$, Daciana Antal ${ }^{6}$, Hubert Orfeuvre ${ }^{7}$, Bernadette Corront ${ }^{8}$, Tony Petrella ${ }^{9}$, Maya Hacini ${ }^{10}$, \\ Marie Bouteloup ${ }^{1}$, Gilles Salles ${ }^{1}$ and Bertrand Coiffier $^{1}$
}

\begin{abstract}
Background: Extranodal nasal-type NK/T-cell lymphoma is a rare and severe disease. Considering the rarity of this lymphoma in Europe, we conducted a multicentric retrospective study on nasal-type NK/T cell lymphoma to determine the optimal induction strategy and identify prognostic factors.

Methods: Thirty-six adult patients with nasal-type NK/T-cell lymphoma were recruited and assessed. In total, $80 \%$ of patients were classified as having upper aerodigestive tract NK/T-cell lymphoma (UNKTL) and $20 \%$ extra-upper aerodigestive tract NK/T-cell lymphoma (EUNKTL).

Results: For advanced-stage disease, chemotherapy alone (CT) was the primary treatment ( $84 \%$ vs. $10 \%$ for combined $\mathrm{CT}$ + radiation therapy (RT), respectively), while for early-stage disease, $50 \%$ of patients received the combination of CT + RT and $50 \% \mathrm{CT}$ alone. Five-year overall survival (OS) and progression-free survival (PFS) rates were $39 \%$ and $33 \%$. Complete remission (CR) rates were significantly higher when using CT + RT (90\%) versus CT alone (33\%) ( $p<0.0001)$. For early-stage disease, $C R$ rates were $37 \%$ for $C T$ alone versus $100 \%$ for $C T+$ RT. Quality of response was significantly associated with survival, with 5 -year OS being $80 \%$ for CR patients versus $0 \%$ for progressive disease patients $(p<0.01)$.
\end{abstract}

Conclusion: Early RT concomitantly or sequentially with CT led to improved patient outcomes, with quality of initial response being the most important prognosticator for 5-year OS.

Keywords: Extra nodal NK/T cell, Radiotherapy plus chemotherapy, Complete response, KPI index

\section{Background}

Extranodal nasal-type NK/T-cell lymphoma is a rare and severe disease, occurring more frequently in Asia and South America than in Europe and North America [1-4]. This type of disease represents a distinct entity among T-cell lymphomas according to the World Health Organization (WHO) classification, [5] being found in both the nasal cavity and extranasal sites [6-8]. The disease is characterized histologically by the local invasion

\footnotetext{
*Correspondence: anne-sophie.michallet@chu-lyon.fr

'Department of Hematology, Centre Hospitalier universitaire Lyon Sud, Pierre Benite, France

${ }^{11}$ Department of Hematology, Centre Hospitalier Lyon Sud, 165 chemin du grand revoyet, 69495, Pierre Bénite, France

Full list of author information is available at the end of the article
}

and necrosis of natural killer (NK) cells or T-cells with an invariable Epstein-Barr virus (EBV) infection. In published studies involving adults with a median age of 50 years, $60-90 \%$ of lymphomas were localized in the nasal and upper airway regions, with the remaining found in extranasal sites $[2,9,10]$. Due to the low incidence of the disease, only a few randomized controlled trials have been undertaken [11-13]. Previous studies showed that 5-year overall survival (OS) rates were less than $40 \%$, with progression usually occurring within 2 years [2,7,9-15]. However, the early use of sequential radiotherapy (RT) and chemotherapy (CT) for localized nasal NK/T-cell $[13,16]$ lymphoma was shown to be a successful therapy, which cured approximately half of patients $[1,17]$. In most patients with advanced disease

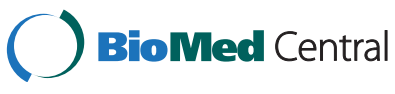


(stage III/IV), the clinical course is highly aggressive, with frequent CT resistance and poor outcome. CHOPbased therapy $[18,19]$ was often used, but associated without satisfactory results. However, recent combination therapies involving L-asparaginase have improved the outcome in high-risk, refractory, or relapsed patients [20-22]. The optimal therapy for advanced-stage or relapsed and refractory disease is yet to be established, although the results of several recent prospective trials showed improved results using CT or CT + RT [20,2325]. Considering the rarity of this lymphoma in Europe, we conducted a multicentric retrospective study on nasal-type NK/T cell lymphoma. To this end, we reviewed the clinical and biological characteristics as well as treatments of 36 patients, with outcomes analyzed according to disease responses in order to determine the optimal induction strategy and identify prognostic factors.

\section{Results}

\section{Patient characteristics}

Our study included 36 patients with a median age of 49 years (range: 22 to 80 ), comprising 24 males and 11 females (ratio: 2.18:1). The majority of patients (75\%) were younger than 60 years. Among the 36 patients, 29 $(80 \%)$ were classified as upper aerodigestive tract NK/T cell lymphoma (UNKTL) versus 7 (20\%) patients as extra-upper aerodigestive tract NK/T cell lymphoma (EUNKTL). In addition, $72 \%$ of UNKTL patients had local invasiveness greater than T3 with TNM classification. According to the Ann Arbor staging system, 10 (28\%) patients were categorized as stage I, six (17\%) as stage II, and $20(55 \%)$ as stage IV. All EUNKTL patients $(\mathrm{n}=7)$ were considered to be stage IV. Furthermore, $75 \%$ of patients had a good performance status $(0-1)$. The most frequently involved sites were the nose (69\%), paranasal sinus (58\%), palate-pharyngeal (25\%), and bones (22\%). Regional lymphadenopathies were involved in $44 \%$ of cases, bone marrow and central nervous system in $22 \%$ and $11 \%$, respectively. The staging was based on computer tomography and MRI for most of the patients. Positron emission tomography/computed tomography (PET/SCAN) was not used to stage or follow evolution of the disease exept in recent diagnosis of T/NK lymphoma. The most frequent symptoms at diagnosis were obstructive in nature (purulent rhinorrhea, nasal obstruction, sinusitis, and dysphagia) in addition to epistaxis and cervical lymphadenopathy. Hematophagocytosis was observed in three patients. B symptoms were present in $39 \%$ of patients. Overall, 14 (39\%) patients presented lactate dehydrogenase levels above the normal limit, 18 (50 \%) high CRP levels, and 21 (58 \%) increased beta2-microglobulin levels. Lymphopenia was found in 26 (61 \%) patients, anemia in 13 (36\%), and low serum albumin level in 12 (33\%). According to IPI scoring, 23 (64.\%) patients were classified as low-risk (0-2) and 13 (36\%) as high-risk. As a bone marrow biopsy was not performed in one patient, only 35 patients were assessed using PIT scores, revealing 24 (68 \%) patients to be lowrisk versus 11 (32 \%) high-risk. According to Korean Prognostic Index (KPI) scoring, 19 (53 \%) patients were considered low-risk compared to 17 (47 \%) high-risk. Patient characteristics are listed in Table 1.

\section{Treatment modalities}

The different first-line $\mathrm{CT}$ regimens are presented in Table 2. CT alone was the primary treatment for advanced-stage disease $(84 \%$ for CT vs. $10 \%$ for CT + RT), with $82 \%$ of patients receiving anthracycline-based regimens. For the 35 patients receiving $\mathrm{CT}$, forty different protocols were used: anthracycline based regimen, high dose aracytine plus high dose methotrexate, high dose methotrexate plus L-asparaginase, cisplatin based regimen. For early-stage disease, an equal number of patients received CT + RT or CT alone (50 \%-50\%). All seven patients with EUNKTL were administered CT alone. For patients with UNKTL, CT alone was given to 17 (61 \%) patients compared to 10 (36\%) receiving the combination of CT + RT. Patients were treated with a median of 2 CT lines (range: 1 to 4). One patient was lost of view after 6 cycles of chemotherapy without evaluation of the disease response.

\section{Radiation therapy and modalities}

Ten patients received CT $+\mathrm{RT}$. The RT was given with a median dose of 40 gray (40 to 46). Only one patient received RT alone (30 gray) plus corticosteroids because of advaned age and comorbidities.

\section{Response to treatment}

At the end of treatment, complete remission (CR) was observed in $48 \%$ of patients, while the remaining $52 \%$ experienced partial response or progressive disease. For the entire cohort, CR rates were $33 \%$ for CT alone compared with $90 \%$ for $\mathrm{RT}+\mathrm{CT}$. In the $\mathrm{CT}$ group, there was no significant difference $(\mathrm{p}=0.77)$ in $\mathrm{CR}$ rates according to the type of regimen: $52 \%$ of patients achieved $\mathrm{CR}$ with an anthracycline-based regimen, $66 \%$ with the combination of methotrexate and Lasparaginase, and $34 \%$ with cisplatin-based regimens

For UNKTL patients, CR rates were only $50 \%$ for CT alone versus $90 \%$ for $\mathrm{RT}+\mathrm{CT}$. However, UNKTL patients with $\mathrm{CT}+\mathrm{RT}$ have more favorable prognostic parameters than CT alone patients: $20 \%$ stage IV versus $61 \%, 10 \%$ of elevated LDH versus $44 \%$; but the same percentage of local invasiveness and regional lymphadenopathy involved (70 \% vs $67 \%$ and $40 \%$ vs $44 \%$, 
Table 1 Clinical characteristics of the 36 patients diagnosed with NK/T cell lymphoma 'nasal type' Number of patients

Median age (years ; range)

Age $>\mathbf{6 0}$ years, $\mathbf{n}(\%)$

Gender (male - female)

WHO performance status, $\mathbf{n}(\%)$

$0-1$

2

3-4

Local invasiveness in Upper

NK / T lymphoma: T3 and T4, n (\%)

Signs and symptoms, n (\%)

Purulent rhinorrhea

Nasal obstruction or edema

Sinusitis

Epistaxis

Pharyngitis

Orbital edema or uveitis

Dysphagia

Nerve VII, palsy

B symptoms, $\mathbf{n}$ (\%)

Anatomic category, n (\%)

Upper NKTT lymphoma

Extra upper NKT lymphoma

Sites of localization, $\mathbf{n}(\%)$

Nose

Paranasal sinus

Nodes

Palate - pharyngeal

Bone marrow

Orbit

Skin

Lung

Central nervous involvement

Liver

Gastrointestinal tract

Spleen

Testis

Suprarenal gland

Regional lymphadenopathy, n (\%)

Biology, n (\%)

LDH > Upper limit of normal

Lymphopenia

B2 microglobuline > upper limit of normal

CRP > upper limit of normal
Table 1 Clinical characteristics of the 36 patients diagnosed with NK/T cell lymphoma 'nasal type' (Continued)

36
$49(22-80)$
$9(25)$
$24-11$
$27(75)$
$6(17)$
$3(8)$
$21(72)$

Anemia 13 (36)

Serum albumin $<30 \mathrm{mg} / \mathrm{L}$

$12(33)$

Hemophagocytic syndrome, n (\%)

3 (8)

Ann Arbor staging, $\mathbf{n}(\%)$

IE

$10(28)$

IIE

$6(17)$

IV

$20(55)$

IPI score, $\mathbf{n}$ (\%)

$0-1$ (low risk)

16 (44)

2 (low intermediate risk)

3 (high intermediate risk)

Korean NK/T cell prognostic index, $n$ (\%)

0 (low risk)

1 (low intermediate risk)

2 (high intermediate risk)

3-4 (high risk)

$9(25)$

PIT score, $\mathbf{n}$ (\%)

14 (39)

0 (low risk)

1 (low intermediate)

2 (high intermediate risk)

3-4 (high risk)

IPI : International Prognostic Index, PIT : Prognostic Index for PTCL/NOS, LDH : Lactate dehydrogenase.
$21(58)$

$16(44)$

9 (25)

8 (22)

4 (11)

$4(11)$

4 (11)

4 (11)

4 (11)

3 (8)

$2(5)$

$1(3)$

$1(3)$

$16(44)$

14 (39)

$22(61)$

$21(58)$

$18(50)$ respectively). One patient received RT alone, but experienced disease progression on this regimen.

Among the low stage group (stage I-II), the distribution between the two treatment modalities is balanced confirming the better outcome with the combination $\mathrm{CT}+\mathrm{RT}$. However in the stage IV patients, the difference in the distribution between CT and CT + RT could create a significant bias in favor of the CT + RT group.

For EUNKTL patients, all were treated with anthracycline-based regimens, resulting in a CR rate of $43 \%$. Responses to the different modalities are provided in Table 3.

\section{Overall survival and progression-free survival}

The 5-year OS and PFS rates were $39 \%$ and $33 \%$, respectively (Figure 1A and Figure 1B). Eighty-two percent of patients died from disease progression, one from abdominal infection, and one from secondary acute leukemia 6 years after autologous transplantation. In univariate analysis, male sex, B symptoms, disease stage, lactate dehydrogenase level, prognostic indexes (IPI, PIT, and $\mathrm{KPI}$ ), and quality of response (CR versus no response (or PD)) were found to be significantly associated 
Table 2 First line treatment of the patients with T/NK cell lymphoma

\begin{tabular}{|c|c|c|c|c|c|}
\hline & Number of patients $n(\%)$ & Stage I -II n (\%) & Stage IV n(\%) & UNKTL n (\%) & EUNKTL n (\%) \\
\hline First line therapy & $36(100)$ & $16(45)$ & $20(55)$ & $29(80)$ & $7(20)$ \\
\hline Chemotherapy alone & $25(69)$ & $8(50)$ & $17(85)$ & $18(62)$ & $7(100)$ \\
\hline Chemotherapy + radiotherapy & $10(28)$ & $8(50)$ & $2(10)$ & $10(35)$ & 0 \\
\hline Radiotherapy alone & $1(3)$ & 0 & $1(5)$ & $1(3)$ & 0 \\
\hline Anthracycline-based regimen & $26(74)$ & $11(69)$ & $15(79)$ & $20(71)$ & $6(86)$ \\
\hline $\begin{array}{l}\text { High-dose methotrexate }+ \text { high-dose } \\
\text { aracytine regimen }\end{array}$ & $4(11)$ & $2(12)$ & $2(11)$ & $3(11)$ & $1(14)$ \\
\hline High-dose methotrexate + L-asparaginase & $2(6)$ & $1(7)$ & $1(5)$ & $2(7)$ & 0 \\
\hline Cisplatin-based regimen & $3(9)$ & $2(12)$ & $1(5)$ & $3(11)$ & 0 \\
\hline
\end{tabular}

UNKTL: upper aerodigestive NK/T cell lymphoma, EUNKTL : extra-upper aerodigestive NK/T cell lymphoma.

with OS and PFS. Extensive disease stage, local invasiveness, high lactate dehydrogenase levels, and high-risk scores according to the IPI, PIT, and KPI classifications were related to poor survival. Quality of response was significantly associated with survival, with 5-year OS rates being $80 \%$ for patients in CR versus $0 \%$ for those with progressive disease $(\mathrm{p}<0.01)$. When we focused on the UNKTL population, the best results were obtained when treatment consisted of CT + RT, with a statistically significant difference in terms of 5-year OS and PFS. The 5-year OS rate was $75 \%$ for patients receiving CT +

Table 3 Response rate after first line therapy in patient with NK/T lymphoma

\begin{tabular}{lll}
\hline & Response \\
\cline { 2 - 3 } & CR (\%) & PD (\%) \\
\hline All patients & 48 & 52 \\
First line therapy & 33 & 67 \\
Chemotherapy alone & 90 & 10 \\
Chemotherapy + radiotherapy & 0 & 100 \\
Radiotherapy alone & 69 & 31 \\
Stage I and II & 37 & 63 \\
Chemotherapy alone & 100 & 0 \\
Chemotherapy + radiotherapy & 31 & 69 \\
Stage IV & 31 & 69 \\
Chemotherapy alone & 50 & 50 \\
Chemotherapy + radiotherapy & 0 & 100 \\
Radiotherapy alone & 50 & 50 \\
UNKTL & 29 & 71 \\
Chemotherapy alone & 90 & 10 \\
Chemotherapy + radiotherapy & 0 & 100 \\
Radiotherapy alone & & 57 \\
EUNKTL & 43 & \\
Chemotherapy alone & & \\
\hline OR overall response PD: progrssve & & \\
\hline
\end{tabular}

OR: overall response, PD: progressive disease, UNKTL: Upper NK/T Lymphoma, EUNKTL: Extra Upper NK/T Lymphoma 35 patients analyzed because 1 patient lost of view for response.
RT compared with $35 \%$ for those receiving CT alone $(\mathrm{p}=0.041)$ (Figure 2A). Accordingly, PFS was significantly higher in patients treated with $\mathrm{RT}+\mathrm{CT}$ versus $\mathrm{CT}$ alone $(\mathrm{p}=0.0063)$ (Figure $2 \mathrm{~B})$. Lymphopenia, low serum albumin level, high CRP level, and the classification into UNKTL or EUNKTL were statistically linked to OS or PFS.

\section{Discussion}

Extranodal nasal-type NK/T-cell lymphoma is considered a distinct clinicopathological entity according to the WHO classification of lymphoid tumors, being more frequent in Asia and Central and South America than in Western countries $[2,3,5,9,17,26]$. In a recent international multicenter study reported by the International Peripheral T-cell Lymphoma Project, median survival time for patients with NK/T-cell lymphoma was 8 months, being the worst among all peripheral T-cell lymphomas included in the study [17]. To date, only a few studies have compared the clinical and pathologic features of patients with nasal or extranasal disease $[7,10,17]$.

In our study, 36 French patients, all of European descent, observed over a 22-year period were diagnosed with nasal-type NK/T cell lymphoma..Main patient characteristics, such as age, sex ratio, B symptoms, and clinical aspects of the disease, were comparable to those previously reported $[17,27,28]$. At diagnosis, $80 \%$ of tumors involved the upper aerodigestive tract, including the nasal and oral cavity, as well as the naso-, oro- and hypopharynx, while $20 \%$ were extranasal. Disease presentation in our population was aggressive, with $65 \%$ of UNKTL patients presenting stage IV at diagnosis. Although extranasal cases presented more adverse clinical features, no statistical differences were found in terms of OS or PFS between UNKTL and EUNKTL patients. This absence in OS difference may be accounted for by the more advanced disease stage of the UNKTL population. Previous studies reported bone marrow and central nervous system involvement at presentation to be rare, affecting $3 \%$ and $7 \%$ of cases, respectively [8,29-31]. In 


\section{A. Overall survival}

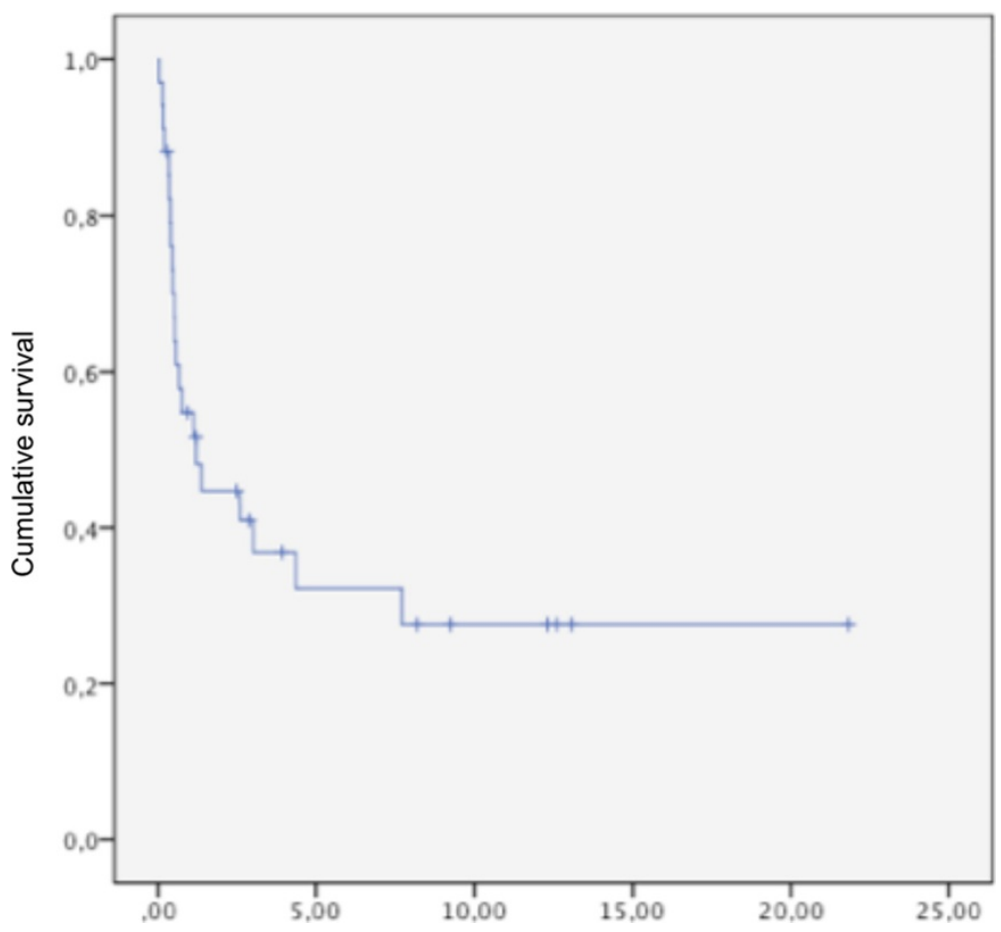

B. Progression Free Survival

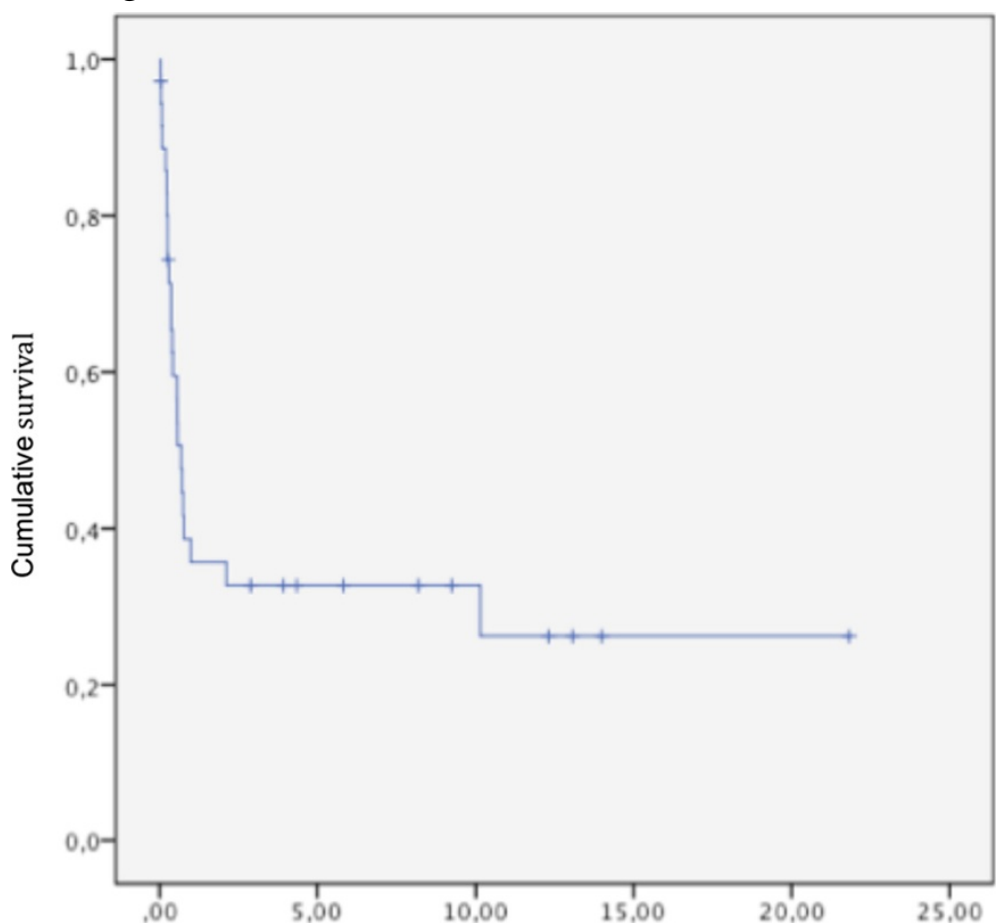

Figure 1 (A) Overall survival (OS) for the entire cohort. (B) Progression-free survival (PFS) for the entire cohort. 
A. Overall survival according to type of treatment

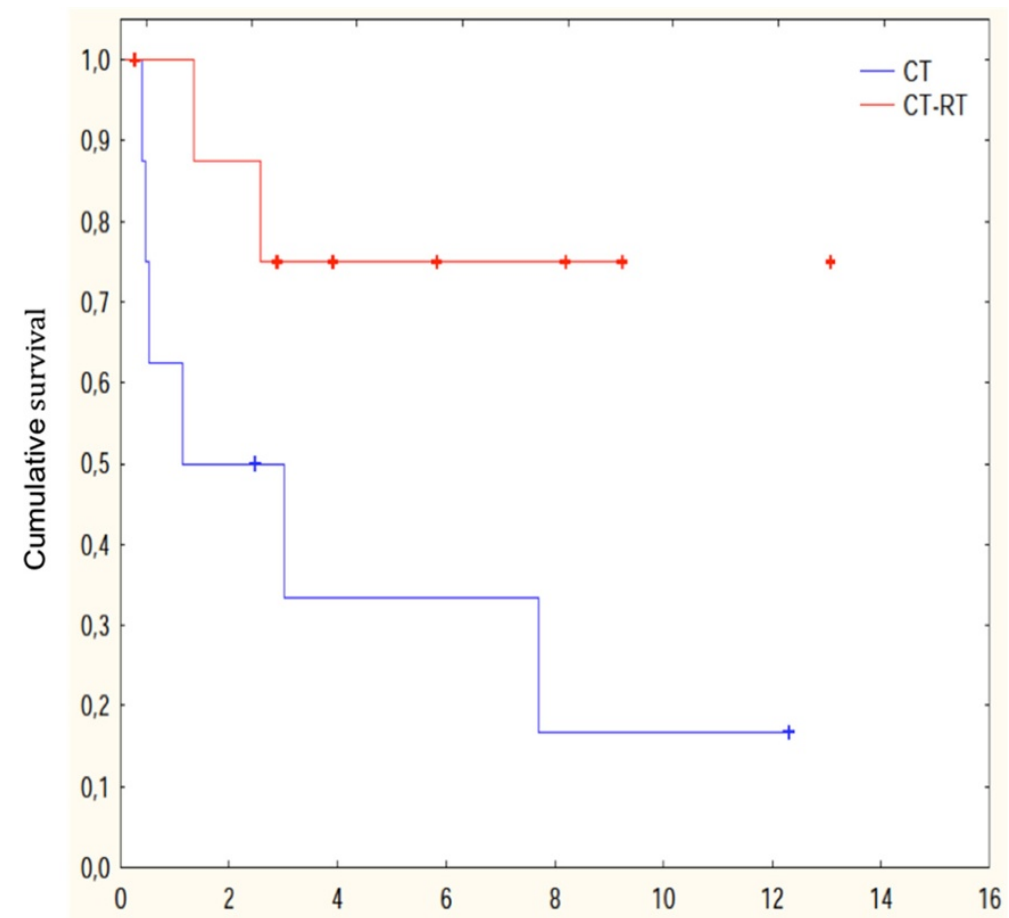

B. Progression free survival according to type of treatment

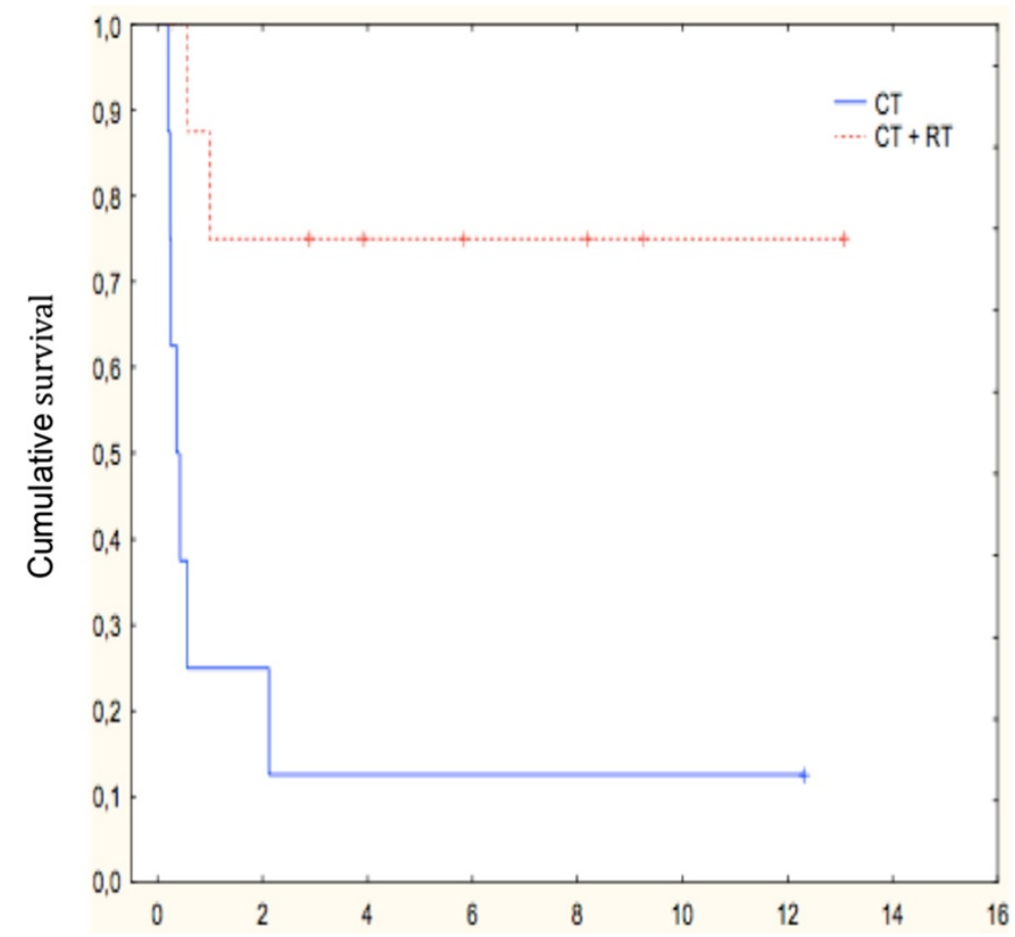

Figure 2 (A) Overall survival according to type of treatment. CT: chemotherapy; RT: radiotherapy; CT + RT: chemotherapy plus radiotherapy. (B) Progression-free survival according to type of treatment. 
our study, however, bone marrow and central nervous system involvement was observed in $22 \%$ and $11 \%$ of patients, respectively. However, regional node involvement was found to be more frequent, affecting $44 \%$ of patients $[32,33]$. In line with previous studies, we identified several variables associated with poor survival, notably regional lymph node involvement [34], local invasiveness [34-37], elevated lactate deshydrogenase $[1,34]$, poor performance status [1], and B symptoms $[1,37,38]$.

Several staging systems have been proposed in respect to nasal NK/T-cell lymphoma in order to predict prognosis. The Ann-Arbor staging system, while designed mainly for Hodgkin lymphoma, is not always accurate in the case of NK-cell lymphomas. In a number of studies on nasal NK-cell lymphoma, the involvement of areas outside the nasal cavity, including the paranasal sinuses, nasopharynx, and orbits, was defined as stage IE disease. In this case, the Ann-Arbor staging system cannot be used to determine the extent of the disease. Thus, for our patients, we scored local invasiveness greater than or equal to T3 according to the TNM classification. Overall, $72 \%$ of UNKTL patients had a local invasiveness $>$ T3, which was associated with worse survival.

Several studies investigated the impact of IPI in patients with nasal NK/T-cell lymphoma [7,9,13]. However, the use of this index has been controversial $[13,34,39,40]$, as in a number of studies, only a small proportion of NK/T-cell lymphoma patients (up to $7 \%$ ) were categorized as high-risk $[1,13,34,41,42]$. Assigning a conventional IPI score appears to be of limited value, since most cases of NK/T-cell lymphomas are localized and result in a low score, despite survival being poor.

Lee et al. [9] developed the KPI, a prognostic model based on four risk factors: B symptoms, advanced stage, elevated lactate dehydrogenase levels, and involvement of regional lymph nodes. When analyzed according to the number of risk factors, the 5-year OS rate was $81 \%$ for patients with no risk factors (score 0) and 7-15\% for those with three to four (scores 3-4). Our data validated the prognostic impact of the KPI, with 5-year OS rates being $60 \%$ for patients with score 0 versus $17 \%$ for those with score 4 . This index appears more accurate than the IPI score in distinguishing high-risk groups, potentially being the most appropriate prognostic scoring system for patients with nasal-type NK/T lymphoma [43].

There are currently a few randomized trials evaluating the different therapeutic options for nasal-type NK/T-cell lymphomas. The majority of studies are retrospective in nature and almost all are conducted in the geographical areas where the tumor is prevalent. Most authors reported on the use of RT alone or combined with $\mathrm{CT}$, with RT being associated with high remission rates and prolonged survival, mainly in the case of localized disease $[34,40,44,45]$. In a study of 82 patients with localized disease, early RT was shown to be the only independent prognostic factor, with 5-year OS being significantly better in patients receiving $>54 \mathrm{~Gy}$ [46]. There appears to be a consensus that the optimal dose is 50 Gy, to be delivered to both the nasal cavity and sinuses. Nevertheless, concurrent CT may improve both local and systemic disease control. When comparing $\mathrm{CT}$ alone to $\mathrm{RT}$ alone or $\mathrm{CT}+\mathrm{RT}, \mathrm{CR}$ rates were significantly higher in patients treated with $\mathrm{CT}+\mathrm{RT}$ $[13,28,34,44,47]$. In addition, two recent reports on CT + RT for localized disease (stage IE to IIE) showed improved results compared to the historical controls using RT alone $[24,48]$.

In our study, the overall response rate was $48 \%$, with progressive disease observed in $52 \%$ of patients and no partial response. Combined therapy comprising RT and anthracycline-based CT regimens was associated with higher $\mathrm{CR}$ rates and longer OS compared to $\mathrm{CT}$ or RT alone, even in advanced-stage disease (CR rate of $31 \%$ vs $50 \%$ for $\mathrm{CT}$ and $\mathrm{CT}+\mathrm{RT}$, respectively). However, the $\mathrm{CT}+\mathrm{RT}$ cohort has a better prognostic profile than the CT population and this difference will create a significant bias in favor of CT + RT group, especially for this high stage group. No CR was recorded for RT alone, although this treatment was only administered to one elderly patient with a non optimal dose of $40 \mathrm{~Gy}$. In the two published metaanalyses, first-line $\mathrm{CT}$ regimens involved $\mathrm{CHOP}, \mathrm{CHOP}-$ like schedules, etoposide, ifosfamide, or cisplatin. In our study, however, the disease did not respond well to these combinations. The introduction of L-asparaginase-containing regimens led to further improvements, as most studies using asparaginase-based regimens in a relapsed or refractory setting reported response rates of around $50 \%$, with 5 -year OS being $65 \%$ (86 \% for localized disease and $38 \%$ for advanced stage) [20,22,25,48-50]. In our study, the different CT regimens were compared, with no statistical difference (but low numbers of patients in each type) found in CR rates according to the type of regimen. The use of L-asparaginase-based regimens in induction therapy did not improve CR rates, although only four patients were administered this regimen. Data regarding the use of L-asparaginase as first-line therapy is therefore still needed.

For all patients, 5-year OS and PFS rates were $39 \%$ and $33 \%$, respectively. In addition, the quality of response after first-line treatment was found to be crucial for survival, with 5-year OS being $80 \%$ in CR patients compared to $0 \%$ in progressive disease patients.

\section{Conclusions}

In our study, the early use of RT concomitantly or sequentially with $\mathrm{CT}$ was shown to improve patient 
outcome, especially in the case of localized disease, and even in patients presenting aggressive forms. Based on these positive results, patients with localized disease should be administered RT $+\mathrm{CT}$. The use of $\mathrm{L}$ asparaginase-based regimens as first-line therapy should be considered for patients with disseminated disease, although prospective trials are still needed to confirm improved survival rates associated with this therapeutic approach.

\section{Patients and Methods}

\section{Patients and staging evaluation}

Between January 1989 and September 2010, 36 patients were recruited in seven hematological centers in France. All the patients in this series been entirely of European descent (no patients were of Asia or south America descent). Patients were required to fulfill the WHO criteria for clinicopathologic diagnosis and classification of NK/ T-cell lymphoma [5]. All biopsied tissues were critically reviewed. The following data was collected: gender, age, clinical characteristics (performance status and symptoms), biological parameters (lactate dehydrogenase, Creactive protein $[\mathrm{CRP}]$, and serum albumin), radiological presentation, and histopathological reports describing angiocentricity, angioinvasion, necrosis zones, and polymorphism of individual cells. Immunohistochemical studies had to be positive for NK/T-cell markers, including CD2, CD3, or CD56 cytotoxic molecule (TIA-1 or granzyme $\mathrm{B}$ ), and for EBV-encoded small RNA, and negative for B-cell markers, such as CD20 or CD79. Patients with blastic NK-cell lymphoma/leukemia, aggressive NK-cell lymphoma/leukemia, and unspecified peripheral $\mathrm{T}$-cell lymphoma were excluded from the analysis. Scores for the International Prognostic Index [51] (IPI), Korean Prognostic Index (KPI) [9], and Prognostic Index for PTCL/NOS [52] (PIT) were calculated for all patients. We separately analyzed the survival of patients with upper aerodigestive tract NK/T-cell lymphoma (UNKTL) and extra-upper aerodigestive tract NK/ T-cell lymphoma (EUNKTL) [1,27]. UNKTL included all lymphomas confined to the nasal cavity, nasopharynx, and upper aerodigestive tract, whereas lymphomas at all other sites were considered to be EUNKTL. Patients with primary lesions within the nasal cavity and secondary lesions in other organs were classified as UNKTL. Local invasiveness was defined in accordance with the 2002 TNM classification of the American Joint Committee on Cancer [9].

\section{Outcomes and treatment strategies}

CT schedules, RT dosages, and chronological sequence of treatments were analyzed for each patient. In terms of $\mathrm{CT}$, treatments were based on anthracycline, aracytine or cisplatin regimens (doxorubicin, cyclophosphamide, vindesine, bleomycin, and prednisone [ACVBP]) for 17 (49 \%) patients; cyclophosphamide, doxorubicin, vincristine, and prednisone (CHOP) for 9 (25\%) patients; cyclophosphamide, vincristine, prednisone, doxorubicin, and methotrexate (COPADM) followed by cyclophosphamide, cytosine arabinoside, and etoposide (CYVE) for four (11\%) patients; etoposide, methylprednisolone, cytosine arabinoside, and cisplatin (ESHAP) and dexamethasone (DHAP) for 3 (8.3\%) patients; high-dose methotrexate plus L-asparaginase for 2 (6\%) patients. Autologous bone marrow transplantation was performed as first-line consolidation on one patient. The different treatment schedules are listed in Table 2. Studied outcomes were treatment response, progression-free survival (PFS), and OS, with treatment response being evaluated at the end of treatment according to the standardized response criteria of Cheson et al. [53].

Regarding RT treatment, the median dose was 40 grays (Gy). All patients received RT from a linear accelerator with 4 megavolt (MV), $6 \mathrm{MV}$ or $10 \mathrm{MV}$ photons to achieve dose homogeneity. Generally, the planning target volume included all macroscopic lesions, the paranasalsinuses, the nasopharynx, the upper gum, and the palate with adequate margins. Regardless of primary tumor localization, elective cervical lymph node irradiation was not delivered unless the neck was involved clinically. The most common field arrangement was two lateral opposing photons fields with supplementation between the medial canthus by appropriate energy of electron.

\section{Statistical analysis}

OS and PFS were estimated using the Kaplan-Meier product-limit method. OS was measured from the date of diagnosis to death or last follow-up visit. Unadjusted Cox proportional hazards models were employed to make group comparisons for baseline and treatment characteristics and Kaplan -Meier curves were used to quantify the percentage of patients who were free of recurrence or those who stay alive over time. A p-value $<0.05$ was considered statistically significant, with twosided significance tests used for all $\mathrm{p}$-values.

Competing interest

The author(s) indicated no potential conflicts of interest.

\section{Author details}

${ }^{1}$ Department of Hematology, Centre Hospitalier universitaire Lyon Sud, Pierre Benite, France. ${ }^{2}$ Department of Anatomopathology, Centre Hospitalier universitaire Lyon Sud, Pierre Benite, France. ${ }^{3}$ Department of Anatomopathology, Besançon, France. ${ }^{4}$ Department of Hematology, Centre Hospitalier universitaire Besançon, Besançon, France. ${ }^{5}$ Department of Hematology, Centre Leon Berard, Lyon, France. ' Department of Hematology, Centre Hospitalier de Roanne, Roanne, France. ${ }^{7}$ Department of Hematology, Centre Hospitalier de Bourg en Bresse, Bresse, France. ${ }^{8}$ Department of Hematology, Centre Hospitalier Anneçy, Anneçy, France. ${ }^{9}$ Department of Pathology, Centre Hospitalier universitaire de Dijon, Dijon, France.

${ }^{10}$ Department of Hematology, Centre Hospitalier de Chambery, Chambery, 
France. " Department of Hematology, Centre Hospitalier Lyon Sud, 165 chemin du grand revoyet, 69495, Pierre Bénite, France.

\section{Authors' contributions}

Conception and design: AC, A-SM and BC Provision of study materials or patients: all of the co authors Collection and assembly of data: AC and A-SM. Data analysis and interpretation: AC, A-SM and BC Manuscript writing: AC, A$\mathrm{SM}, \mathrm{GS}$ and $\mathrm{BC}$. Final approval of the manuscript: All the co authors.

\section{Received: 22 April 2012 Accepted: 8 June 2012}

Published: 8 June 2012

\section{References}

1. Lee J, Park YH, Kim WS, Lee SS, Ryoo BY, Yang SH, Park KW, Kang JH, Park JO, Lee SH, et al: Extranodal nasal type NK/T-cell lymphoma: elucidating clinical prognostic factors for risk-based stratification of therapy. Eur J Cancer 2005, 41:1402-1408.

2. Oshimi K, Kawa K, Nakamura S, Suzuki R, Suzumiya J, Yamaguchi M, Kameoka J, Tagawa S, Imamura N, Ohshima K, et al: NK-cell neoplasms in Japan. Hematology 2005, 10:237-245.

3. Quintanilla-Martinez L, Franklin JL, Guerrero I, Krenacs L, Naresh KN, Rama-Rao C, Bhatia K, Raffeld M, Magrath IT: Histological and immunophenotypic profile of nasal NK/T cell lymphomas from Peru: high prevalence of p53 overexpression. Hum Pathol 1999, 30:849-855.

4. Rudiger T, Weisenburger DD, Anderson JR, Armitage JO, Diebold J, MacLennan KA, Nathwani BN, Ullrich F, Muller-Hermelink HK: Peripheral T-cell lymphoma (excluding anaplastic large-cell lymphoma): results from the Non-Hodgkin's Lymphoma Classification Project. Ann Oncol 2002, 13:140-149.

5. Chan JK, Quintanilla-Martinez L, Ferry JA, Peh SC: Extranodal NK/T-cell lymphoma, nasal type. In WHO Classification of Tumours of Haematopoietic and Lymphoid Tissues. Edited by Swerdlow SH, Campo E, Harris NL, et al. Lyon, France: International Agency for Research on Cancer; 2008.

6. Jaffe ES, Krenacs L, Raffeld M: Classification of cytotoxic T-cell and natural killer cell lymphomas. Semin Hematol 2003, 40:175-184.

7. Lim ST, Hee SW, Quek R, Lim LC, Yap SP, Loong EL, Sng I, Tan LH, Ang MK, Ngeow J, et al: Comparative analysis of extra-nodal NK/T-cell lymphoma and peripheral T-cell lymphoma: significant differences in clinical characteristics and prognosis. Eur J Haematol 2008, 80:55-60.

8. Oshimi K: Progress in understanding and managing natural killer-cell malignancies. Br J Haematol 2007, 139:532-544.

9. Lee J, Suh C, Park YH, Ko YH, Bang SM, Lee JH, Lee DH, Huh J, Oh SY, Kwon $\mathrm{HC}$, et al: Extranodal natural killer T-cell lymphoma, nasal-type: a prognostic model from a retrospective multicenter study. J Clin Oncol 2006, 24:612-618.

10. Pagano L, Gallamini A, Trape G, Fianchi L, Mattei D, Todeschini G, Spadea A, Cinieri S, lannitto E, Martelli M, et al: NK/T-cell lymphomas 'nasal type': an Italian multicentric retrospective survey. Ann Oncol 2006, 17:794-800.

11. Kwong YL, Anderson BO, Advani R, Kim WS, Levine AM, Lim ST: Management of T-cell and natural-killer-cell neoplasms in Asia: consensus statement from the Asian Oncology Summit 2009. Lancet Oncol 2009, 10:1093-1101.

12. Bossard C, Belhadj K, Reyes F, Martin-Garcia N, Berger F, Kummer JA, Briere J, Baglin AC, Cheze S, Bosq J, et al: Expression of the granzyme B inhibitor $\mathrm{PI} 9$ predicts outcome in nasal NK/T-cell lymphoma: results of a Western series of 48 patients treated with first-line polychemotherapy within the Groupe d'Etude des Lymphomes de l'Adulte (GELA) trials. Blood 2007, 109:2183-2189.

13. Chim CS, Ma SY, Au WY, Choy C, Lie AK, Liang R, Yau CC, Kwong YL: Primary nasal natural killer cell lymphoma: long-term treatment outcome and relationship with the International Prognostic Index. Blood 2004, 103:216-221.

14. Ng SB, Lai KW, Murugaya S, Lee KM, Loong SL, Fook-Chong S, Tao M, Sng I: Nasal-type extranodal natural killer/T-cell lymphomas: a clinicopathologic and genotypic study of 42 cases in Singapore. Mod Pathol 2004, 17:1097-1107.

15. Yong $W$, Zheng W, Zhang Y, Zhu J, Wei Y, Zhu D, Li J: L-asparaginasebased regimen in the treatment of refractory midline nasal/nasal-type T/NK-cell lymphoma. Int J Hematol 2003, 78:163-167.

16. Isobe K, Uno T, Tamaru J, Kawakami H, Ueno N, Wakita H, Okada J, Itami J, Ito H: Extranodal natural killer/T-cell lymphoma, nasal type: the significance of radiotherapeutic parameters. Cancer 2006, 106:609-615.

17. Au WY, Weisenburger DD, Intragumtornchai T, Nakamura S, Kim WS, Sng I, Vose J, Armitage JO, Liang R: Clinical differences between nasal and extranasal natural killer/T-cell lymphoma: a study of 136 cases from the International Peripheral T-Cell Lymphoma Project. Blood 2009, 113:3931-3937.

18. Kwong YL, Chan AC, Liang R, Chiang AK, Chim CS, Chan TK, Todd D, Ho FC: CD56+ NK lymphomas: clinicopathological features and prognosis. $\mathrm{Br} J$ Haematol 1997, 97:821-829.

19. Suzuki R, Suzumiya J, Yamaguchi M, Nakamura S, Kameoka J, Kojima H, Abe M, Kinoshita T, Yoshino T, Iwatsuki K, et al: Prognostic factors for mature natural killer (NK) cell neoplasms: aggressive NK cell leukemia and extranodal NK cell lymphoma, nasal type. Ann Oncol, 21:1032-1040

20. Jaccard A, Gachard N, Marin B, Rogez S, Audrain M, Suarez F, Tilly H, Morschhauser F, Thieblemont $C$, Ysebaert L, et al: Efficacy of L-asparaginase with methotrexate and dexamethasone (AspaMetDex regimen) in patients with refractory or relapsing extranodal NK/T-cell lymphoma, a phase 2 study. Blood 2011, 117:1834-1839.

21. Jaccard A, Petit B, Girault S, Suarez F, Gressin R, Zini JM, Coiteux V, Larroche C, Devidas A, Thieblemont C, et al: L-asparaginase-based treatment of 15 western patients with extranodal NK/T-cell lymphoma and leukemia and a review of the literature. Ann Oncol 2009, 20:110-116.

22. Yong W, Zheng W, Zhu J, Zhang Y, Wang X, Xie Y, Lin N, Xu B, Lu A, Li J: $L$-asparaginase in the treatment of refractory and relapsed extranodal NK/T-cell lymphoma, nasal type. Ann Hematol 2009, 88:647-652.

23. Girinsky T, Lapusan S, Ribrag V, Koscielny S, Ferme C, Carde P: Phase II study of concomitant chemoradiotherapy in bulky refractory or chemoresistant relapsed lymphomas. Int I Radiat Oncol Biol Phys 2005, 61:476-479.

24. Kim SJ, Kim K, Kim BS, Kim CY, Suh C, Huh J, Lee SW, Kim JS, Cho J, Lee GW, et al: Phase II trial of concurrent radiation and weekly cisplatin followed by VIPD chemotherapy in newly diagnosed, stage IE to IIE, nasal, extranodal NK/T-Cell Lymphoma: Consortium for Improving Survival of Lymphoma study. J Clin Oncol 2009, 27:6027-6032.

25. Kwong YL, Yamaguchi M, Maeda Y, et al: Phase II study of SMILE chemothearpy for newly-diagnosed stage IV, relapsed or refractory extranodal NK/T-cell lymphoma, nasal type: NKTSG study. Haematologica, 95

26. Barrionuevo C, Zaharia M, Martinez MT, Taxa L, Misad O, Moscol A, Sarria G, Guerrero I, Casanova L, Flores C, Zevallos-Giampietri EA: Extranodal NK/T-cell lymphoma, nasal type: study of clinicopathologic and prognosis factors in a series of 78 cases from Peru. Appl Immunohistochem Mol Morphol 2007, 15:38-44.

27. Lee J, Kim WS, Park YH, Park SH, Park KW, Kang JH, Lee SS, Lee SI, Lee SH, Kim K, et al: Nasal-type NK/T cell lymphoma: clinical features and treatment outcome. Br J Cancer 2005, 92:1226-1230

28. Li CC, Tien HF, Tang JL, Yao M, Chen YC, Su IJ, Hsu SM, Hong RL: Treatment outcome and pattern of failure in 77 patients with sinonasal natural killer/T-cell or T-cell lymphoma. Cancer 2004, 100:366-375.

29. Kim GE, Cho JH, Yang WI, Chung EJ, Suh CO, Park KR, Hong WP, Park IY, Hahn JS, Roh JK, Kim BS: Angiocentric lymphoma of the head and neck: patterns of systemic failure after radiation treatment. J Clin Oncol 2000, 18:54-63.

30. Vose J, Armitage J, Weisenburger D: International peripheral T-cell and natural killer/T-cell lymphoma study: pathology findings and clinical outcomes. J Clin Oncol 2008, 26:4124-4130.

31. Wong KF, Chan JK, Cheung MM, So JC: Bone marrow involvement by nasal NK cell lymphoma at diagnosis is uncommon. Am J Clin Pathol 2001, 115:266-270.

32. Kim TM, Lee SY, Jeon YK, Ryoo BY, Cho GJ, Hong YS, Kim HJ, Kim SY, Kim CS, Kim S, et al: Clinical heterogeneity of extranodal NK/T-cell lymphoma, nasal type: a national survey of the Korean Cancer Study Group. Ann Oncol 2008, 19:1477-1484.

33. Li YX, Liu QF, Fang H, Qi SN, Wang H, Wang WH, Song YW, Lu J, Jin J, Wang SL, et al: Variable clinical presentations of nasal and Waldeyer ring natural killer/T-cell lymphoma. Clin Cancer Res 2009, 15:2905-2912

34. You JY, Chi KH, Yang MH, Chen CC, Ho CH, Chau WK, Hsu HC, Gau JP, Tzeng $\mathrm{CH}$, Liu JH, et al: Radiation therapy versus chemotherapy as initial 
treatment for localized nasal natural killer (NK)/T-cell lymphoma: a single institute survey in Taiwan. Ann Oncol 2004, 15:618-625.

35. Li YX, Coucke PA, Li JY, Gu DZ, Liu XF, Zhou LQ, Mirimanoff RO, Yu ZH, Huang YR: Primary non-Hodgkin's lymphoma of the nasal cavity: prognostic significance of paranasal extension and the role of radiotherapy and chemotherapy. Cancer 1998, 83:449-456.

36. Logsdon MD, Ha CS, Kavadi VS, Cabanillas F, Hess MA, Cox JD: Lymphoma of the nasal cavity and paranasal sinuses: improved outcome and altered prognostic factors with combined modality therapy. Cancer 1997, 80:477-488

37. Robbins KT, Fuller LM, Vlasak M, Osborne B, Jing BS, Velasquez WS, Sullivan JA: Primary lymphomas of the nasal cavity and paranasal sinuses. Cancer 1985, 56:814-819.

38. Kim WS, Song SY, Ahn YC, Ko YH, Baek CH, Kim DY, Yoon SS, Lee HG, Kang WK, Lee HJ, et al: CHOP followed by involved field radiation: is it optimal for localized nasal natural killer/T-cell lymphoma?. Ann Oncol 2001, 12:349-352.

39. Aviles A, Diaz NR, Neri N, Cleto S, Talavera A: Angiocentric nasal T/natural killer cell lymphoma: a single centre study of prognostic factors in 108 patients. Clin Lab Haematol 2000, 22:215-220.

40. Cheung MM, Chan JK, Lau WH, Ngan RK, Foo WW: Early stage nasal NK/T-cell lymphoma: clinical outcome, prognostic factors, and the effect of treatment modality. Int I Radiat Oncol Biol Phys 2002, 54:182-190.

41. Cheung MM, Chan JK, Lau WH, Foo W, Chan PT, Ng CS, Ngan RK: Primary non-Hodgkin's lymphoma of the nose and nasopharynx: clinical features, tumor immunophenotype, and treatment outcome in 113 patients. J Clin Oncol 1998, 16:70-77.

42. Kim K, Kim WS, Jung CW, Im YH, Kang WK, Lee MH, Park CH, Ko YH, Ree HJ, Park K: Clinical features of peripheral T-cell lymphomas in 78 patients diagnosed according to the Revised European-American lymphoma (REAL) classification. Eur J Cancer 2002, 38:75-81.

43. Dearden CE, Johnson R, Pettengell R, Devereux S, Cwynarski K, Whittaker S, McMillan A: Guidelines for the management of mature T-cell and NK-cell neoplasms (excluding cutaneous T-cell lymphoma). Br I Haematol, 153:451-485.

44. Kim K, Chie EK, Kim CW, Kim IH, Park Cl: Treatment outcome of angiocentric T-cell and NK/T-cell lymphoma, nasal type: radiotherapy versus chemoradiotherapy. Jpn J Clin Oncol 2005, $35: 1-5$.

45. Kuo $T$, Shih $L Y$, Tsang NM: Nasal NK/T cell lymphoma in Taiwan: a clinicopathologic study of 22 cases, with analysis of histologic subtypes, Epstein-Barr virus LMP-1 gene association, and treatment modalities. Int J Surg Pathol 2004, 12:375-387.

46. Huang MJ, Jiang Y, Liu WP, Li ZP, Li M, Zhou L, Xu Y, Yu CH, Li Q, Peng F, et al: Early or up-front radiotherapy improved survival of localized extranodal NK/T-cell lymphoma, nasal-type in the upper aerodigestive tract. Int I Radiat Oncol Biol Phys 2008, 70:166-174.

47. Li YX, Yao B, Jin J, Wang WH, Liu YP, Song YW, Wang SL, Liu XF, Zhou LQ, He XH, et al: Radiotherapy as primary treatment for stage IE and IIE nasal natural killer/T-cell lymphoma. J Clin Oncol 2006, 24:181-189.

48. Yamaguchi M, Tobinai K, Oguchi M, Ishizuka N, Kobayashi $Y$, Isobe $Y$, Ishizawa K, Maseki N, Itoh K, Usui N, et al: Phase I/II study of concurrent chemoradiotherapy for localized nasal natural killer/T-cell lymphoma: Japan Clinical Oncology Group Study JCOG0211. J Clin Oncol 2009, 27:5594-5600

49. Obama K, Tara M, Niina K: L-asparaginase-Based induction therapy for advanced extranodal NK/T-cell lymphoma. Int I Hematol 2003, 78:248-250.

50. Yong $W$, Zheng $W$, Zhu J, Zhang Y, Wei Y, Wang X, Lin N, Xie Y, Xu B, Li J: Midline NK/T-cell lymphoma nasal-type: treatment outcome, the effect of L-asparaginase based regimen, and prognostic factors. Hematol Oncol 2006, 24:28-32.

51. A predictive model for aggressive non-Hodgkin's lymphoma: The International Non-Hodgkin's Lymphoma Prognostic Factors Project. N Engl J Med 1993, 329:987-994.

52. Gallamini A, Stelitano C, Calvi R, Bellei M, Mattei D, Vitolo U, Morabito F,

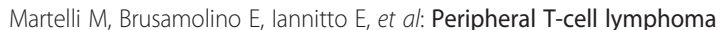
unspecified (PTCL-U): a new prognostic model from a retrospective multicentric clinical study. Blood 2004, 103:2474-2479.
53. Cheson BD: The International Harmonization Project for response criteria in lymphoma clinical trials. Hematol Oncol Clin North Am 2007, 21:841-854.

doi:10.1186/1756-8722-5-27

Cite this article as: Chauchet et al:: Complete remission after first-line radio-chemotherapy as predictor of survival in extranodal NK/T cell lymphoma. Journal of Hematology \& Oncology 2012 5:27.

\section{Submit your next manuscript to BioMed Central and take full advantage of:}

- Convenient online submission

- Thorough peer review

- No space constraints or color figure charges

- Immediate publication on acceptance

- Inclusion in PubMed, CAS, Scopus and Google Scholar

- Research which is freely available for redistribution 